\title{
Effective flexural stiffness for reinforced concrete shear walls having confined boundary elements
}

\author{
Saeid Foroughi*iD, S. Bahadir Yuksel iD \\ Konya Technical University, Department of Civil Engineering, Konya, Turkey
}

\begin{abstract}
In the design of reinforced concrete (RC) shear walls strength, ductility and effective stiffness of the elements must be taken into account and are important parameters in terms of structural safety. Accurate estimation of the ductility and effective stiffnesses of RC members has always been an attractive subject of study as it provides a reliable estimate of the capacity of buildings under seismic loads. In this study, RC shear wall models with different concrete strength, longitudinal and transverse reinforcement ratios were designed to investigate effective section stiffness and coefficients. The effective stiffness of the cracked section in the RC shear walls designed in different parameters were analytically obtained. Analytically investigated parameters were calculated from TBEC (2018), ACI318 (2014), ASCE/SEI41 (2017) and Eurocode8 (2004, 2005) regulations and nonlinear behaviors. The results obtained according to different design parameters were compared and examined. In the relations suggested for the effective section stiffness coefficient, the confining effect is not taken into account as in the regulations. Therefore, it means neglecting the effects of parameters such as concrete strength, confining effect and axial load levels acting on the section. This situation can lead to unrealistic results in the design and evaluation of RC elements. For this reason, determining the moment-curvature relationship in the design and evaluation of $\mathrm{RC}$ elements and obtaining effective section stiffness values are of great importance in order to obtain more realistic results.
\end{abstract}

\section{Keywords}

Shear wall; Nonlinear behavior; Seismic performance; Seismic codes; Effective stiffness; Moment-curvature Received: 01 May 2021; Accepted: 24 June 2021

ISSN: 2630-5763 (online) C 2021 Golden Light Publishing All rights reserved.

\section{Introduction}

The level of accuracy in the estimation of section rigidity plays a very important role in determining realistic values for the structural stiffness and hence the seismic forces imposed. The most significant parameters influencing the effective rigidity, which reflects the effect of cracking as well as the theoretical yielding of RC sections, are determined through the comprehensive moment-curvature analyses of various RC sections [1]. Improper approximation of member stiffness affects the distribution of forces and deformation demands which leads to inaccurate structural response evaluation. Thus, the use of actual effective stiffness based on strength is very important in nonlinear analyses to evaluate the actual performance of the building under seismic conditions [2]. The effective stiffness of RC members is important in the structural design for determining the buckling capacity of a member, and evaluating the elastic deformations and internal forces of a structure [3]. Concrete cracking reduces

\footnotetext{
Corresponding author

Email: saeid.foroughi@yahoo.com
} 
the flexural and shear stiffness of RC members. Therefore, analysing RC structures without considering the cracking effect may not represent actual behavior [4]. For linear analysis, the member stiffnesses control predictions of the period of the structure, the distribution of loads within the structure, and the deformation demands [5].

Cracks in concrete, which reduce the stiffness of $\mathrm{RC}$ elements, occur at loads much smaller than those that correspond to yielding of reinforcement and bearing capacity of elements [6]. The effective stiffness of a structural wall is an important property in the design, which many design codes estimate by the moment of inertia of the wall section with a reduction factor [7]. The magnitude of the effective stiffness depends on the intensity and distribution of stress on a wall cross-section, and the extent of flexural and shear cracking [8]. Kwon and Ghannoum [9] examined the accuracy of the lateral stiffness provisions of international standards for concrete buildings. Sharifi and Shafieian [10] proposed relations to determine the effective stiffness based on statistical analyses on slender and squat walls. Linear regression analyses are applied to determine the relationship between effective stiffness parameters such as axial load, reinforcement ratio, and aspect ratio. Rahimian [11] proposed two methods and formulas for the effective stiffness of the shear wall suitable for design office practice. The proposed methods are capable of predicting the effective stiffness of the shear walls for different loading intensities, as could be related to serviceability or ultimate states. Paulay and Priestley [12] investigated various factors affecting the flexural rigidity of $\mathrm{RC}$ members and proposed average values. Panagiotakos and Fardis [13] developed expressions for yield and ultimate deformation capacities of RC members that are essential for estimating the effective elastic stiffness of cracked RC members.

In widely used regulatory documents and guidelines, the effective rigidity of members is expressed as a proportion of their rigidity, calculated on the basis of the cross-section properties. Several procedures are suggested to considered effective rigidity: Turkish Building Earthquake Code (TBEC) [14], Building Code Requirements for Structural Concrete (ACI 318-14) [15], Seismic Evaluation and Retrofit of Existing Buildings (ASCE/SEI41) [16], Design of structures for earthquake resistance (Eurocode 8) [17] and Design of structures for earthquake resistance: Part 3: Assessment and retrofitting of buildings (Part 3 of Eurocode 8) [18]. To investigate the most significant factors influencing the effective stiffness of RC shear walls and to evaluate the adequacy of the current seismic code specified factors, a comprehensive study has been performed. The effective stiffness of shear walls is obtained by based moment-curvature analyses depending on member properties such as axial load levels, longitudinal reinforcement diameter in the confined boundary regions, transverse reinforcement diameter, transverse reinforcement spacing and concrete compressive strength. The analysis results obtained for different shear wall models are examined by summarizing in graphs.

\section{Effective stiffness of RC shear walls}

\subsection{Effective stiffness coefficient according to moment-curvature relations}

The most significant parameters influencing the effective rigidity, which reflects the effect of cracking as well as the theoretical yielding of RC sections, is determined through the comprehensive moment-curvature analyses of various $\mathrm{RC}$ sections. Effective section stiffness $\left(E I_{e}\right)$ of the cracked section of the RC sections is determined by the ratio corresponding to the yield moment $\left(M_{y}\right)$ and the yield curve $\left(\emptyset_{y}\right)$, taking into account the momentcurvature curvature relationship $\left(E I_{e}=M_{y} / \emptyset_{y}\right)$. Uncracked section stiffness $(E I)$ of the concrete were calculated using the gross moment of inertia (I) of the RC members and modulus of elasticity of the concrete $\left(E_{c}\right)$. For concrete grade, concrete elasticity modulus $\left(E_{c}=3250 \sqrt{f_{c k}}+14000\right)$ $\mathrm{MPa}$ are calculated according to the concrete compressive strengths given in TS500 [19]. Effective stiffness coefficient of RC elements is calculated as $k_{e}=E I_{e} / E I$. 


\subsection{Effective section stiffness coefficient proposed in different seismic codes}

Effective section stiffness coefficients will be used in modelling the sectional properties of $\mathrm{RC}$ structural members within the scope of Strength by Design. Effective cross-sectional stiffness multipliers will only be applied to calculations that are included in earthquake-effect load combinations and under loads entered into these combinations. In the seismic evaluation and retrofit of existing buildings [14-17], the stiffness reduction coefficient values for $\mathrm{RC}$ shear walls are given in Table 1.

\subsection{Effective section stiffness coefficient proposed in TBEC [14]}

Effective cross-sectional stiffnesses $(E I)$ of the RC members designed according to the lumped plastic behavior will be determined according to Eq. (1). Where $M_{y}$ is the yield moment, $\theta_{y}$ is the chord rotation at the yielding end and $L_{s}$ is the shear span. The chord rotation at yielding $\left(\theta_{y}\right)$ in RC elements are calculated by Eq. (2) by linear methods. For nonlinear calculation, chord rotation at yielding $\left(\theta_{y}\right)$ of the RC members is calculated by Equation (3). In Eq. (3); $f_{y e}$ is the expected yield strength of transverse reinforcement $\left(f_{y e}=1.2 f_{y k}\right)$ and $f_{c e}$ expected compressive strength of concrete $\left(f_{c e}=1.3 f_{c k}\right), h$ is the section height, $d_{b}$ is the longitudinal reinforcement diameter and $\emptyset_{y}$ is the yield curvature. $\eta=1$ in shear walls [14].

$(E I)_{e}=\frac{M_{y}}{\theta_{y}} \frac{L_{s}}{3}$

$\theta_{y}=\frac{M_{y} L_{s}}{3 E I}$

$\theta_{y}=\frac{\emptyset_{y} L_{s}}{3}+0.0015 \eta\left(1+1.5 \frac{h}{L_{S}}\right)+\frac{\emptyset_{y} d_{b} f_{y e}}{8 \sqrt{f_{c e}}}$

\subsection{Effective section stiffness coefficient proposed in Part 3 of Eurocode 8 [18]}

Design of structures for earthquake resistance, Part 3; Assessment and Retrofitting of Buildings [18] provides an equation based on moment-to-shear ratio and yield rotation, which can be used for the determination of a more accurate effective stiffness. Both the ultimate level and serviceability level loads are addressed in Part 3 of Eurocode 8 [18] for linear and nonlinear analysis. If the verification is carried out in terms of deformations, deformation demands should be obtained from an analysis of a structural model in which the stiffness of each element is taken to be equal to the mean value of $M_{y} L_{v} / 3 \theta_{y}$, at the two ends of the element. In this calculation the shear span at the end section, $L_{v}$, may be taken to be equal to half the element length. In case the verification is carried out in terms of deformations the corresponding capacity is given by the chord rotation at yielding $\theta_{y}$, evaluated as:

$\theta_{y}=\emptyset_{y} \frac{L_{V}+a_{V} Z}{3}+0.0013+\frac{\varepsilon_{y}}{d-d^{\prime}} \cdot \frac{d_{b L} f_{y}}{6 \sqrt{f_{c}}}$

or from the alternative (and equivalent) expressions for walls of rectangular section:

$\theta_{y}=\emptyset_{y} \frac{L_{V}+a_{V} z}{3}+0.0013+\emptyset_{y} \frac{d_{b L} f_{y}}{8 \sqrt{f_{c}}}$

$\emptyset_{y}$ : is the yield curvature of the end section, $a_{V} z$ : is the tension shift of the bending moment diagram, $z$ : length of internal lever arm, taken equal to $z=$ $0.8 h$ in RC walls with rectangular section, $\varepsilon_{y}$ : is equal to $f_{y} / E_{s}, d$ ve $d^{\prime}:$ are the effective depth and concrete cover, respectively and $d_{b L}$ : is the (mean) diameter of the reinforcement. $a_{V}=0$, if $V_{R c}>$ $M_{y} / L_{s}$ and $a_{V}=1$, if $V_{R c} \leq M_{y} / L_{s} . V_{R, c}$, taken in accordance with [20];

$V_{R d, c}=\left[C_{R d, c} K\left(100 \rho_{1} f_{c k}\right)^{1 / 3}+K_{1} \sigma_{c p}\right] b_{w} d$

Table 1. Flexural stiffness coefficient values for RC shear walls

\begin{tabular}{lcccc}
\hline \multirow{2}{*}{ RC shear walls (Cracked) } & \multicolumn{4}{c}{ Different seismic codes } \\
\cline { 2 - 5 } & TBEC (2018) & ASCE/SEI-41 (2017) & ACI318 (2014) & Eurocode8 (2004) \\
\hline Flexural stiffness coefficient & 0.50 & 0.35 & 0.35 & 0.50 \\
\hline
\end{tabular}


$K=1+\sqrt{\frac{200}{d}} \leq 2, \quad \rho_{1}=\frac{A_{s}}{b_{w} d} \leq 0.02$,

$\sigma_{c p}=\frac{N_{E d}}{A_{c}}<0.2 f_{c d}$

$A_{s l}$ : is the area of the reinforcement, $b_{w}$ : is the smallest width of the cross-section $(\mathrm{mm}), N_{E d}$ : is the axial force in the cross-section due to loading or prestressing (in N) ( $N_{E d}>0$ for compression) and $A_{c}$ : is the area of concrete cross section $\left(\mathrm{mm}^{2}\right)$. The values of $C_{R d, c}, V_{\min }$ and $K_{1}$ for use in a Country may be found in its National Annex.

\section{Material and method}

RC shear wall models with different axial load levels, concrete strength, longitudinal and transverse reinforcement ratios were designed to investigate effective section stiffness. The effective stiffness coefficient of the cracked section of the $\mathrm{RC}$ structural members designed in different parameters were obtained analytically. Analytically investigated parameters were calculated from [14-
18] and moment-curvature relationships of sections. For this analytical study, a rectangular cross-sectional concrete shear wall with $300 \mathrm{~mm} \times$ $3000 \mathrm{~mm}$ dimensions were designed. In TBEC [14] the ratio of the length of the long edge $\left(l_{w}=3000\right.$ $\mathrm{mm})$ of the RC shear walls to the thickness $\left(b_{w}=\right.$ $300 \mathrm{~mm}$ ) in the plan has been determined to be greater than six $\left(l_{w}>6 b_{w}\right)$. As the ratio of the total height $\left(H_{w}=10000 \mathrm{~mm}\right)$ in the RC shear walls to the plan length $\left(l_{w}=3000 \mathrm{~mm}\right)$ is chosen to be greater than two $\left(H_{w} / l_{w}>2\right)$, the shear walls confined boundary elements are formed at both ends of the walls. Confined boundary region dimensions $\left(l_{u}\right)$ of RC shear walls are chosen as 300 $\mathrm{mm} \times 600 \mathrm{~mm}$. The details of the longitudinal and transverse reinforcement placement and ratios of the designed RC shear wall were given in Fig. 1 and Table 2. Longitudinal web reinforcement and longitudinal reinforcements in boundary regions limitations were checked for the designed RC shear wall according to the TBEC [14].

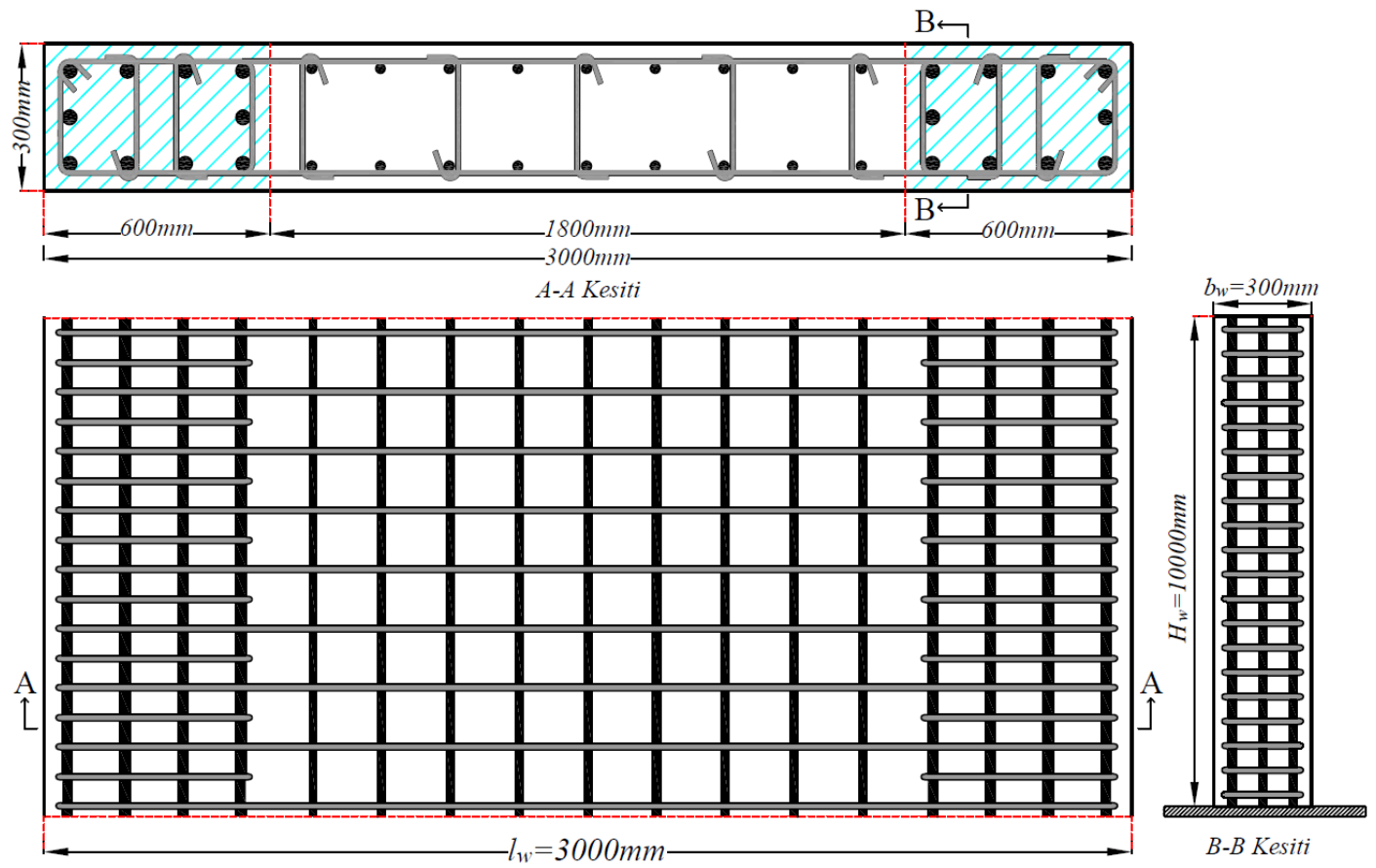

Fig. 1. Cross-sectional dimensions 
Table 2. Details for the designed RC shear wall cross-sections

\begin{tabular}{|c|c|c|c|c|c|}
\hline \multirow{2}{*}{$\begin{array}{c}\text { Concrete } \\
\text { grade } \\
(\mathrm{MPa})\end{array}$} & \multicolumn{2}{|c|}{ Shear wall confined boundary region } & \multicolumn{2}{|c|}{ Shear wall web region } & \multirow{2}{*}{$\begin{array}{l}\text { Axial load } \\
\left(\mathrm{N} / \mathrm{N}_{\max }\right)\end{array}$} \\
\hline & $\begin{array}{c}\text { Longitudinal } \\
\text { reinforcement (LR) }\end{array}$ & $\begin{array}{c}\text { Transverse } \\
\text { reinforcement (TR) }\end{array}$ & $\begin{array}{l}\text { Longitudinal } \\
\text { reinforcement (LR) }\end{array}$ & $\begin{array}{c}\text { Transverse } \\
\text { reinforcement (TR) }\end{array}$ & \\
\hline \multirow{13}{*}{$\begin{array}{l}\mathrm{C} 30 \\
\mathrm{C} 35 \\
\mathrm{C} 40 \\
\mathrm{C} 45 \\
\mathrm{C} 50\end{array}$} & \multirow{9}{*}{$10 \Phi 18 \mathrm{~mm}$} & $\Phi 8 / 50 \mathrm{~mm}$ & \multirow{9}{*}{$18 \Phi 14 \mathrm{~mm}$} & $\Phi 8 / 50 \mathrm{~mm}$ & \multirow{13}{*}{$\begin{array}{l}0.15 \\
0.25 \\
0.35\end{array}$} \\
\hline & & $\Phi 10 / 50 \mathrm{~mm}$ & & $\Phi 10 / 50 \mathrm{~mm}$ & \\
\hline & & $\Phi 12 / 50 \mathrm{~mm}$ & & $\Phi 12 / 50 \mathrm{~mm}$ & \\
\hline & & $\Phi 14 / 50 \mathrm{~mm}$ & & $\Phi 14 / 50 \mathrm{~mm}$ & \\
\hline & & $\Phi 10 / 75 \mathrm{~mm}$ & & $\Phi 10 / 75 \mathrm{~mm}$ & \\
\hline & & $\Phi 10 / 100$ mm & & $\Phi 10 / 100$ mm & \\
\hline & & Q & & स10100 & \\
\hline & & $\Phi 10 / 125$ mm & & $\Phi 10 / 125$ mm & \\
\hline & & $\Phi 10 / 150 \mathrm{~mm}$ & & $\Phi 10 / 150 \mathrm{~mm}$ & \\
\hline & $10 \Phi 14 \mathrm{~mm}$ & \multirow{4}{*}{$\Phi 10 / 50 \mathrm{~mm}$} & & \multirow{4}{*}{$\Phi 10 / 50 \mathrm{~mm}$} & \\
\hline & $10 \Phi 16 \mathrm{~mm}$ & & & & \\
\hline & $10 \Phi 18 \mathrm{~mm}$ & & & & \\
\hline & $10 \Phi 20 \mathrm{~mm}$ & & & & \\
\hline
\end{tabular}

Theoretical moment-curvature analysis for RC members indicating the available bending moment and curvature can be constructed providing that the stress-strain relations for both concrete and steel are known. Moment-curvature relationships were obtained by SAP2000 Software [21] which takes the nonlinear behaviour of materials into consideration. The combined effect of vertical loads and seismic loads $\left(N_{d m}\right)$, gross section area of shear wall shall satisfy the condition $A_{c} \geq N_{d m} /$ $0.35 f_{c k}$ [14]. The moment-curvature relationships of the RC shear wall sections were obtained for $0.15,0.25$ and 0.35 of axial load ratios. To investigate the effect of axial force on the crosssection behaviour; the RC shear walls were investigated under three different axial load levels. The designed RC shear walls are considered to be composed of three components; cover concrete, confined concrete and reinforcement steel. A confined and unconfined concrete model proposed by Mander models [22] used to determine the moment-curvature relationships of RC members. For reinforcement modelling, material parameters for reinforcement given in TBEC [14] was used. The material parameters for concrete and reinforcement steel given in Figure 2 are used. RC members having different geometries were designed considering the regulations of [14-15].
For all RC members, C30, C35, C40, C45 and C50 were chosen as concrete grade and B420C was selected as reinforcement for the reinforcement behaviour model. Due to its insignificant influence, the tensile strength of concrete has been ignored in the moment-curvature analyses.

Different seismic codes provide varying guidelines for modifying the stiffness of RC elements. When performing structural analysis, it is useful to review multiple codes and standards to determine the effective stiffness of elements. Analytically investigated parameters were calculated from different codes and momentcurvature relationships of shear walls. Examination of current codes and earlier studies revealed that effective stiffness is generally expressed on the basis of the level of axial load in shear walls. In this study, the effect of the axial load levels, concrete strength, longitudinal and transverse reinforcement ratios were considered for shear wall sections. This study is based on parametric analysis of the sectional response of a wide range of shear wall sections. The effective stiffness values obtained from the analysis results according to different codes and moment-curvature relationships are presented in detail in the Research Findings and Discussion section. 

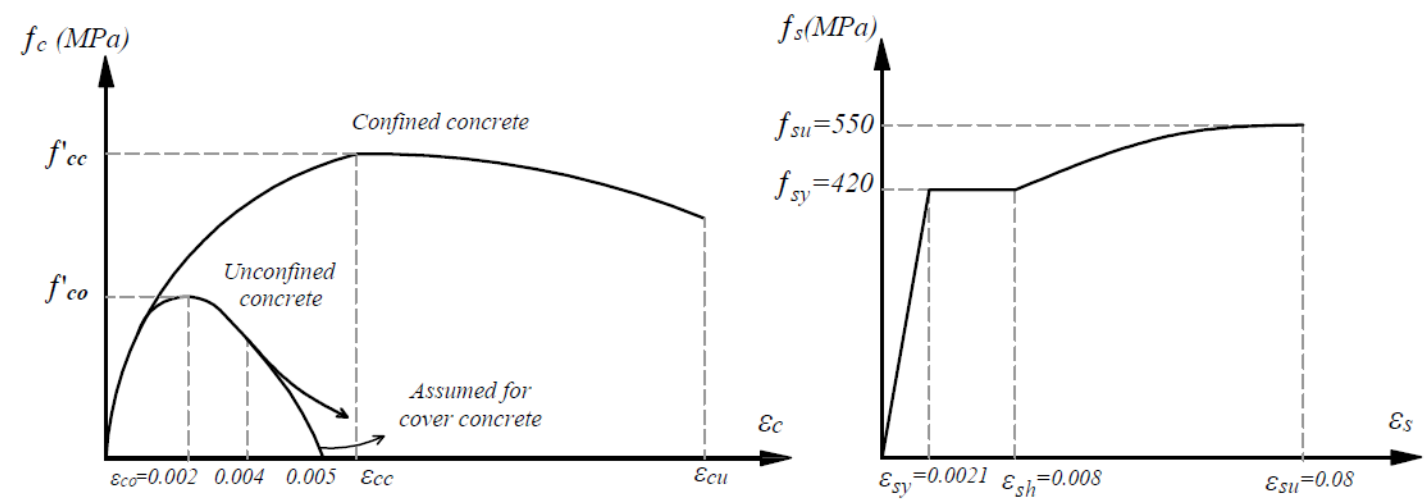

Fig. 2. Stress-strain relationships for concrete and reinforcement [14]

\section{Research findings and discussion}

The results of the parameters investigated for RC shear walls are summarized in the following sections according to different design parameters. The effective stiffness coefficient of the cracked section of the shear wall members designed in different parameters were obtained analytically. According to the results obtained from the numerical analysis, the most important parameters affecting the effective stiffness of RC shear walls are calculated and compared in the continuation of the study. Effective flexural stiffness resulting from concrete cracking depends on some important parameters such as confinement, axial load level, section dimensions and material properties of concrete and reinforcing steel.

\subsection{Nonlinear moment-curvature analysis of reinforced concrete shear walls}

In order to achieve a more accurate simulation of the real structural behaviour, designers need the accurate moment-curvature relationship for $\mathrm{RC}$ members and stress-strain relationships for unconfined and confined concrete. A total of 135 different analyses were performed to determine the moment-curvature relationships and effective stiffness coefficients of rectangular cross-section shear walls with different parameters. Crosssectional analysis is compared according to criteria which can change the effective stiffness of RC shear wall cross-sections. The moment-curvature curves were drawn for different RC shear wall models and were interpreted by comparing the curves. Moment $\left(M_{y}, M_{u}\right)$ and curvature $\left(\emptyset_{y}, \emptyset_{u}\right)$ values were calculated for yield and ultimate conditions from moment-curvature relationships according to different parameters in the designed RC shear wall models (Fig. 3).

It is observed that the variation of the longitudinal reinforcement, transverse reinforcement, concrete strength and axial load levels have an important effect on the momentcurvature behavior of the RC shear walls. With the increasing axial load values (other design parameters constant) yield curvature, yield and ultimate moment values increase, ultimate curvature values decrease. Curvature ductility values of the RC shear walls decrease with increasing axial load ratio. In the RC shear walls yield curvature and yield moment values remain almost constant, ultimate curvature and ultimate moment values decrease with the increase of transverse reinforcement spacing. It is observed that the curvature ductility decreases when the transverse reinforcement spacing is increased. The increase in the transverse reinforcement ratio increases the yield curvature, ultimate moment, ultimate curvature and curvature ductility values, but yield moment values remain almost constant. With the increase in the longitudinal reinforcement ratio, yield and ultimate curvature values remain almost constant, yield and ultimate moment values increase and curvature ductility values decrease. With the increase of concrete compressive strength, yield curvature decreases, yield moment, maximum moment and curvature values increase. 

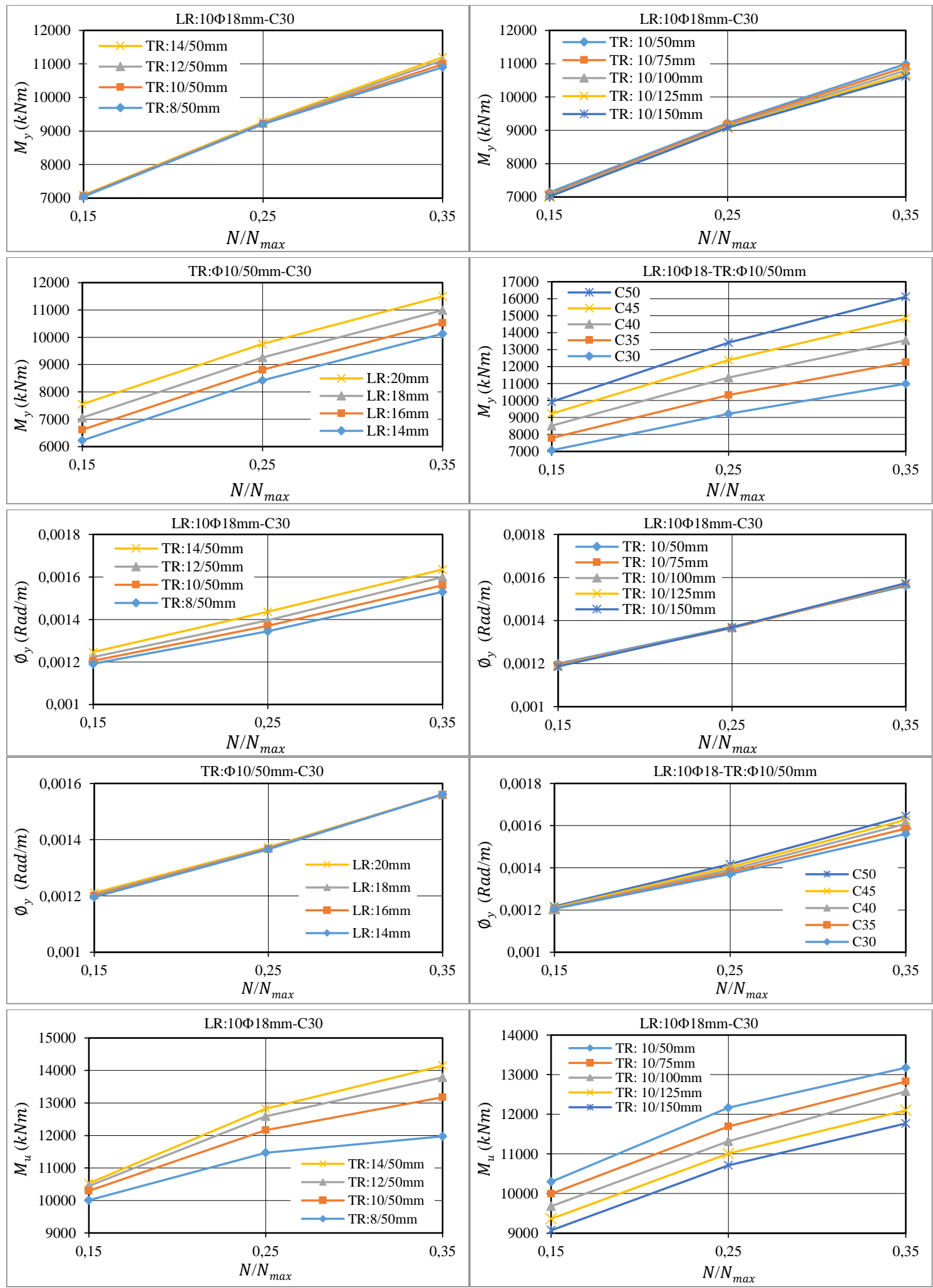

Fig. 3. Influence of $N / N_{\max }$, concrete strength, longitudinal and transverse reinforcement on the moment and curvature 

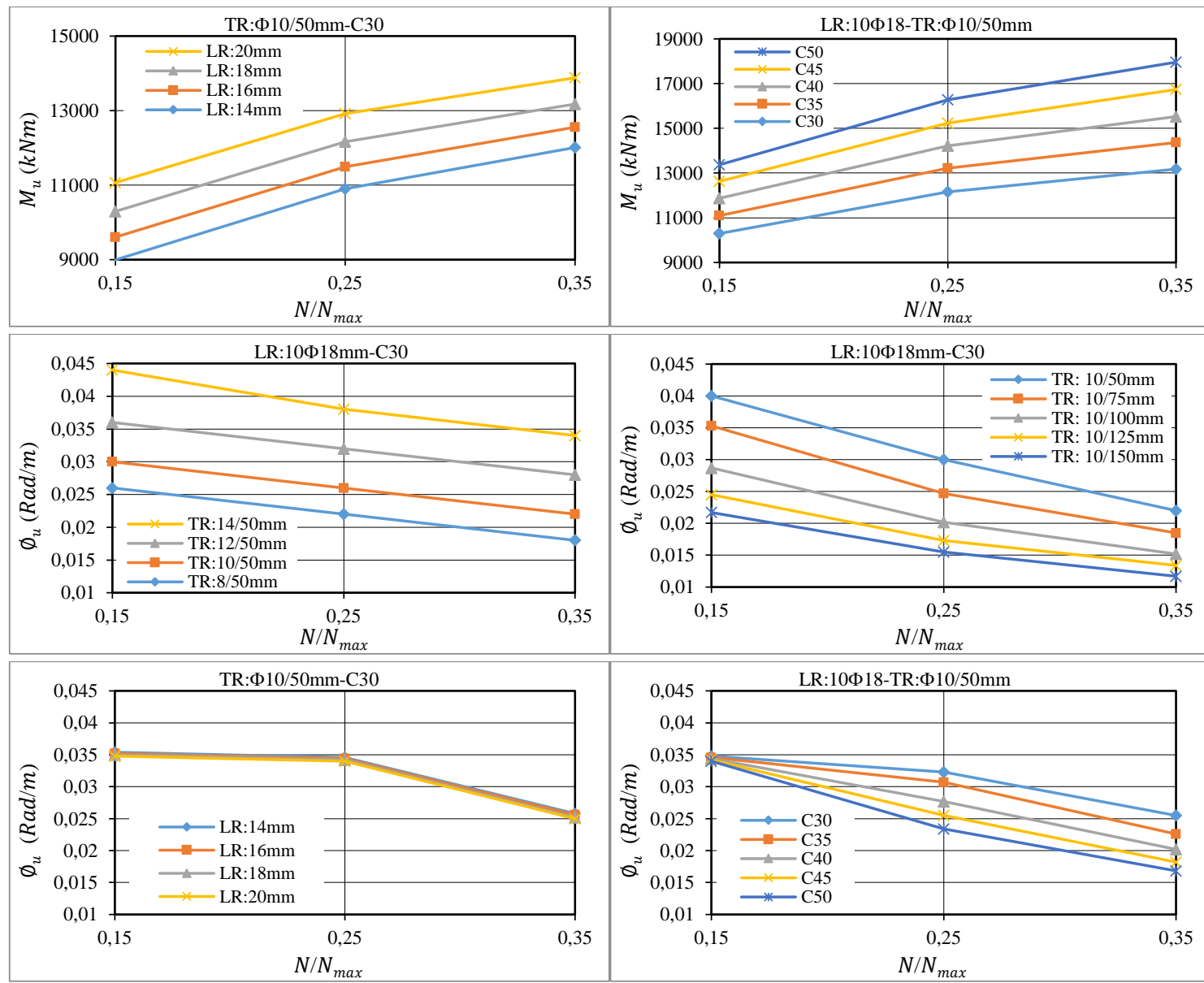

Fig. 3. Cont'd

\subsection{Effective stiffness analysis of reinforced concrete shear walls}

To investigate the most significant factors influencing the effective rigidity of $\mathrm{RC}$ shear walls and to evaluate the adequacy of the current code specified values, a comprehensive study has been performed. The effective stiffness of RC shear walls is obtained by based moment-curvature analyses depending on member properties such as different parameters. The effective stiffness coefficient obtained from analysis for different RC shear walls are examined by summarizing in graphs. The results obtained at the end were examined by comparing them according to different design parameters. The effective stiffness coefficient obtained from the analyzes were compared from moment-curvature relations and different seismic codes [14-15]. The calculated effective stiffness coefficient are comparatively given in Figs. 4-6. Comparison of the effective section stiffness ratios obtained from the analysis results according to different procedures for rectangular shear walls are given in Fig. 7.

In ACI318 (2014), the effective stiffness of an $\mathrm{RC}$ structural wall up to yielding is estimated by its cross-sectional moment of inertia with a reduction factor to account for the influence of the flexural and shear cracking. $0.35 E_{c} I_{c}$ for beams and cracked walls, $0.70 E_{c} I_{c}$ for uncracked walls. In ASCE/SEI41 [13], $E I_{\text {eff }}$ for cracked walls is specified as $0.35 E_{c} I_{g}$. 

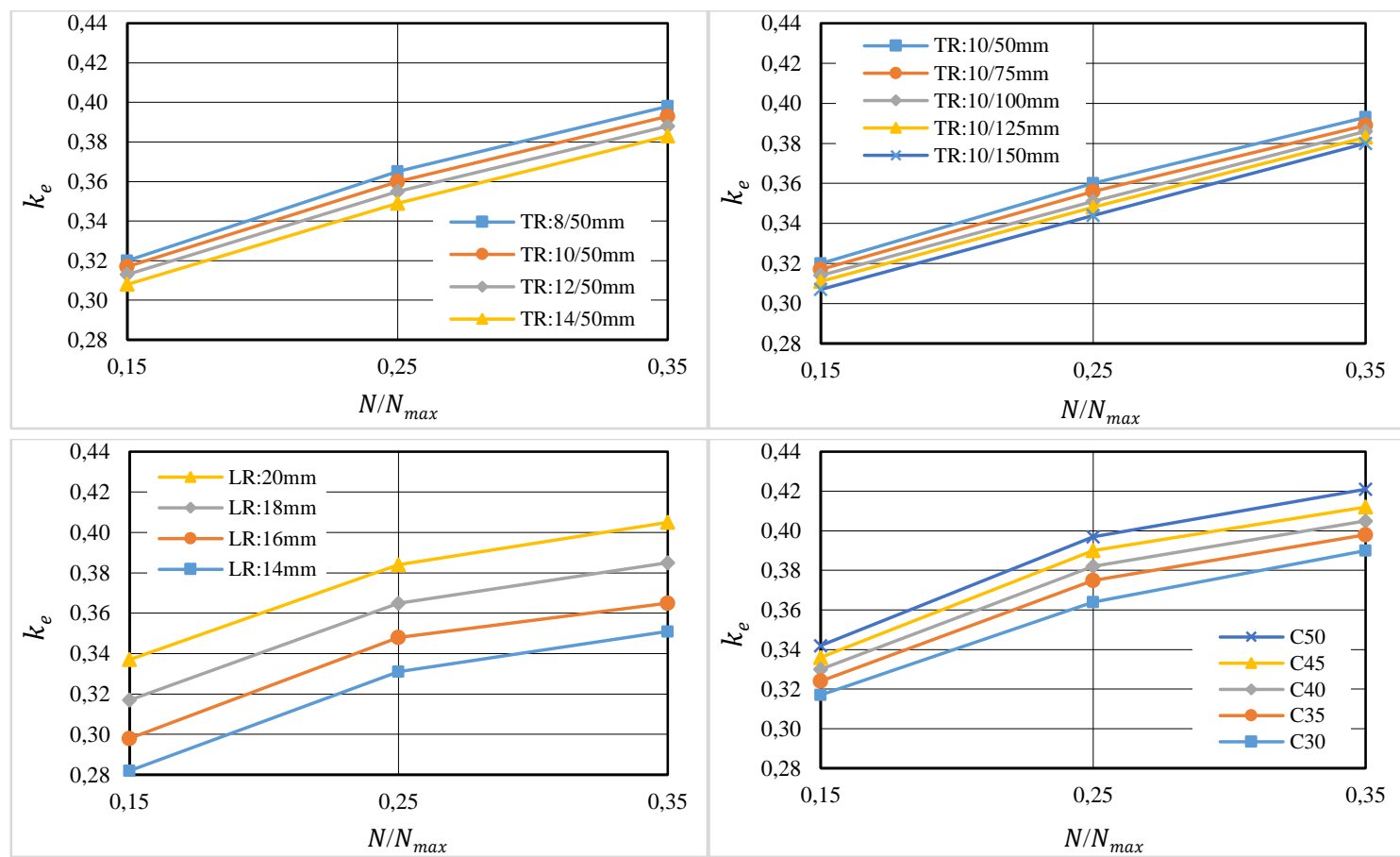

Fig. 4. $k_{e}-N / N_{\max }$ relation according to moment-curvature relationships
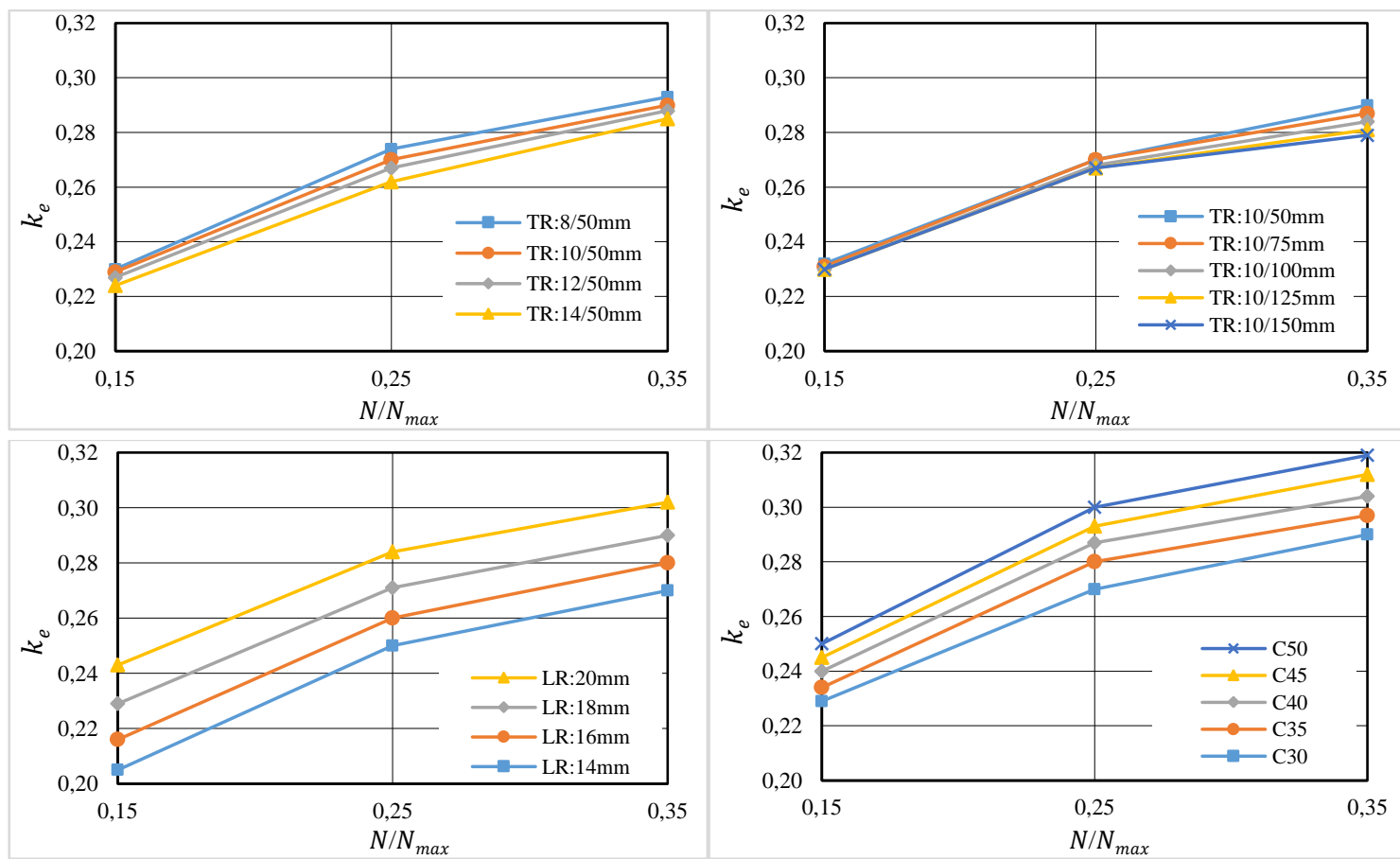

Fig. 5. $k_{e}-N / N_{\max }$ relation according to the lumped plastic behavior given in TBEC (2018) 

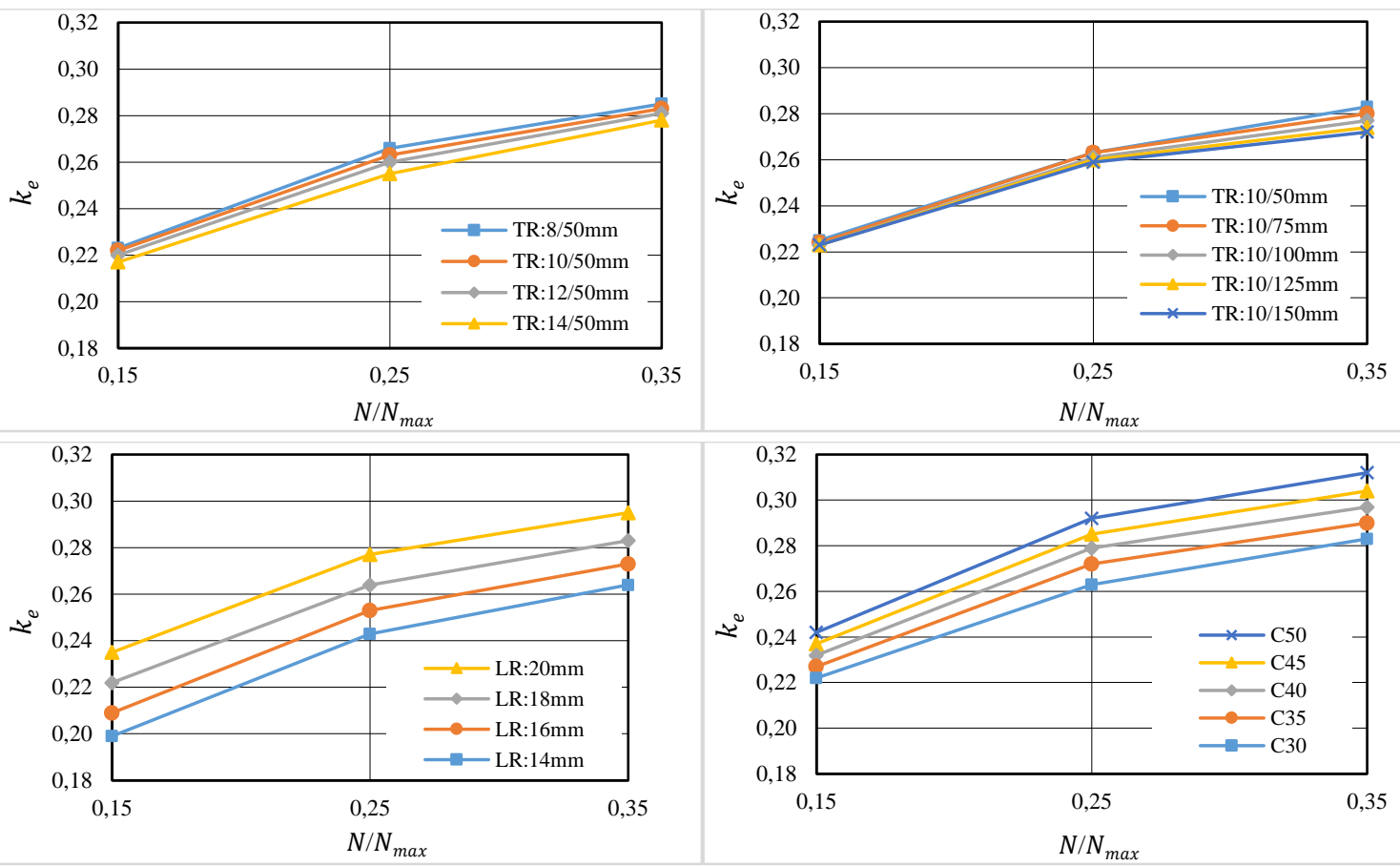

Fig. 6. $k_{e}-N / N_{\max }$ relation according to Part 3 of Eurocode8 (2005)
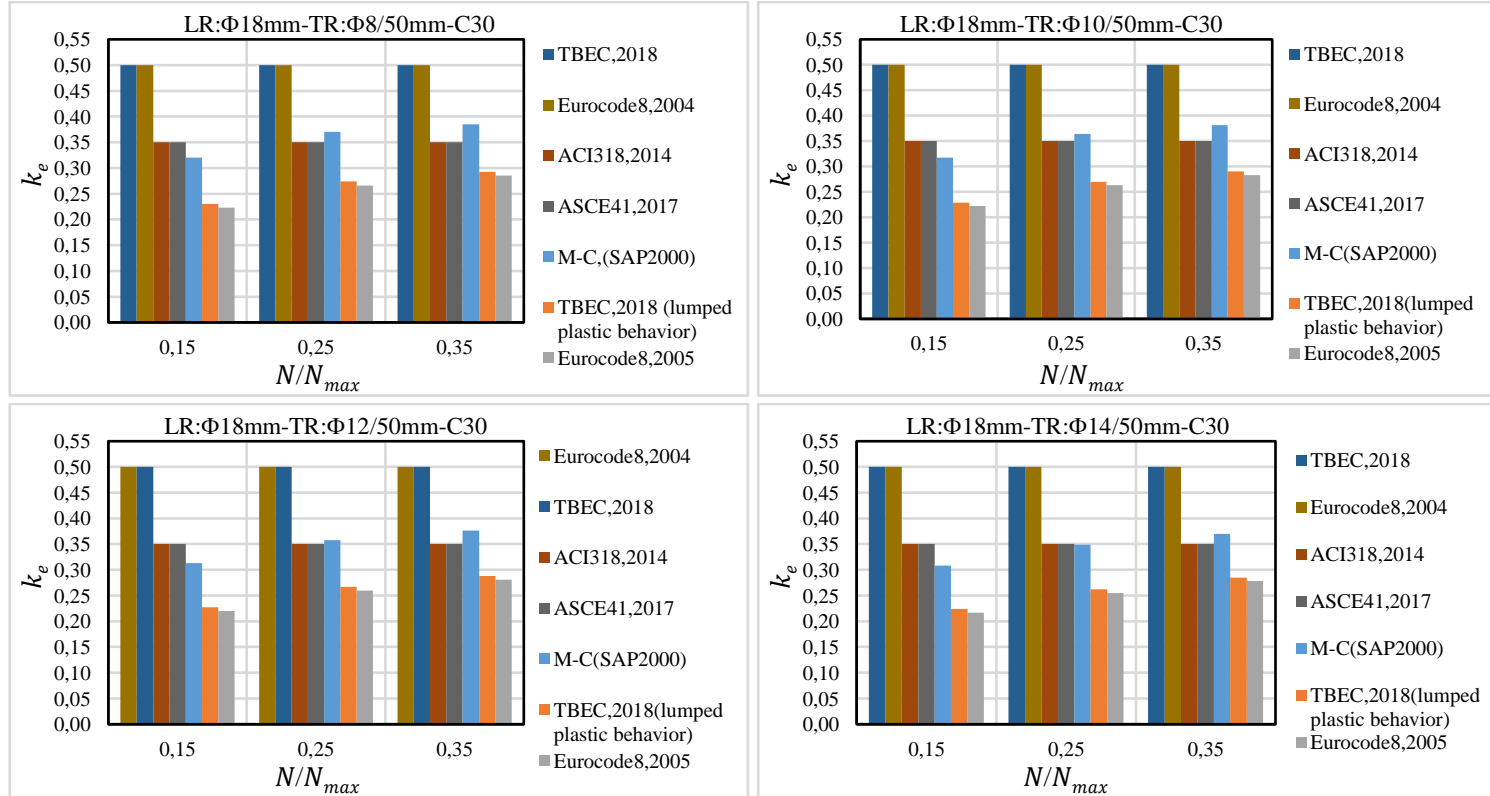

a) Different transverse reinforcement diameters

Fig. 7. Effective section stiffness ratios according to different parameters 

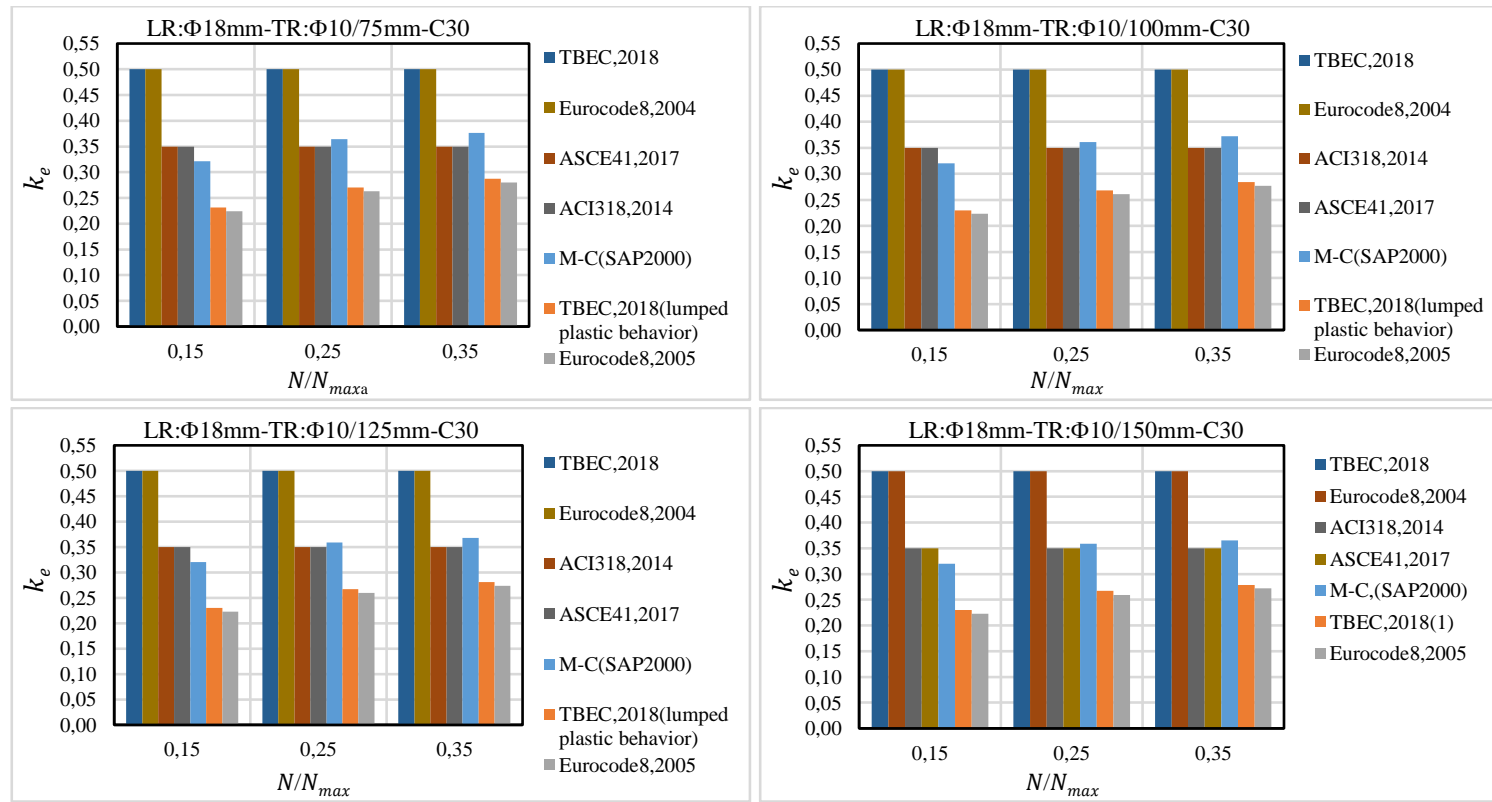

b) Different transverse reinforcement spacing
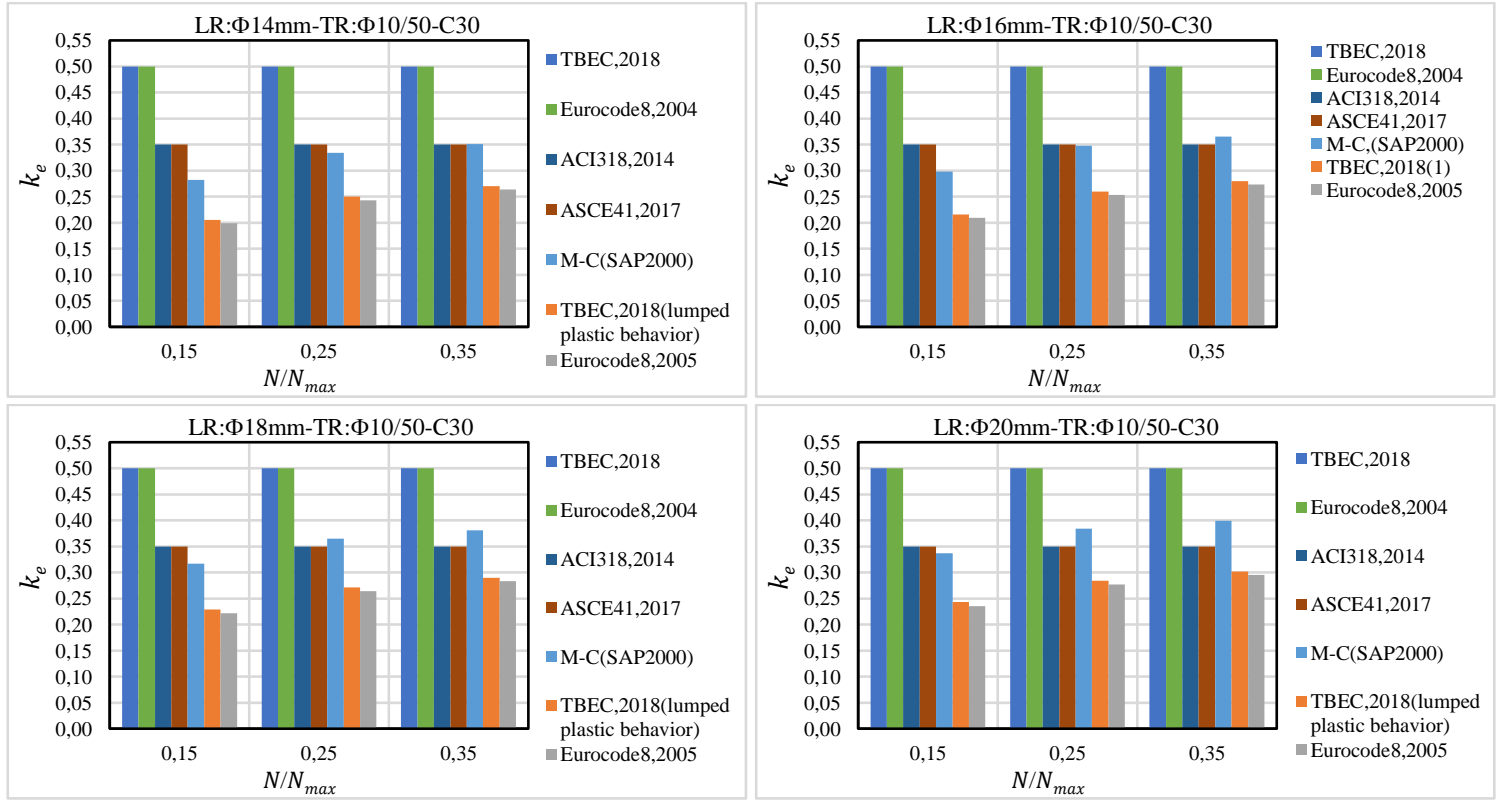

c) Different longitudinal reinforcement diameters

Fig. 7. Cont'd 

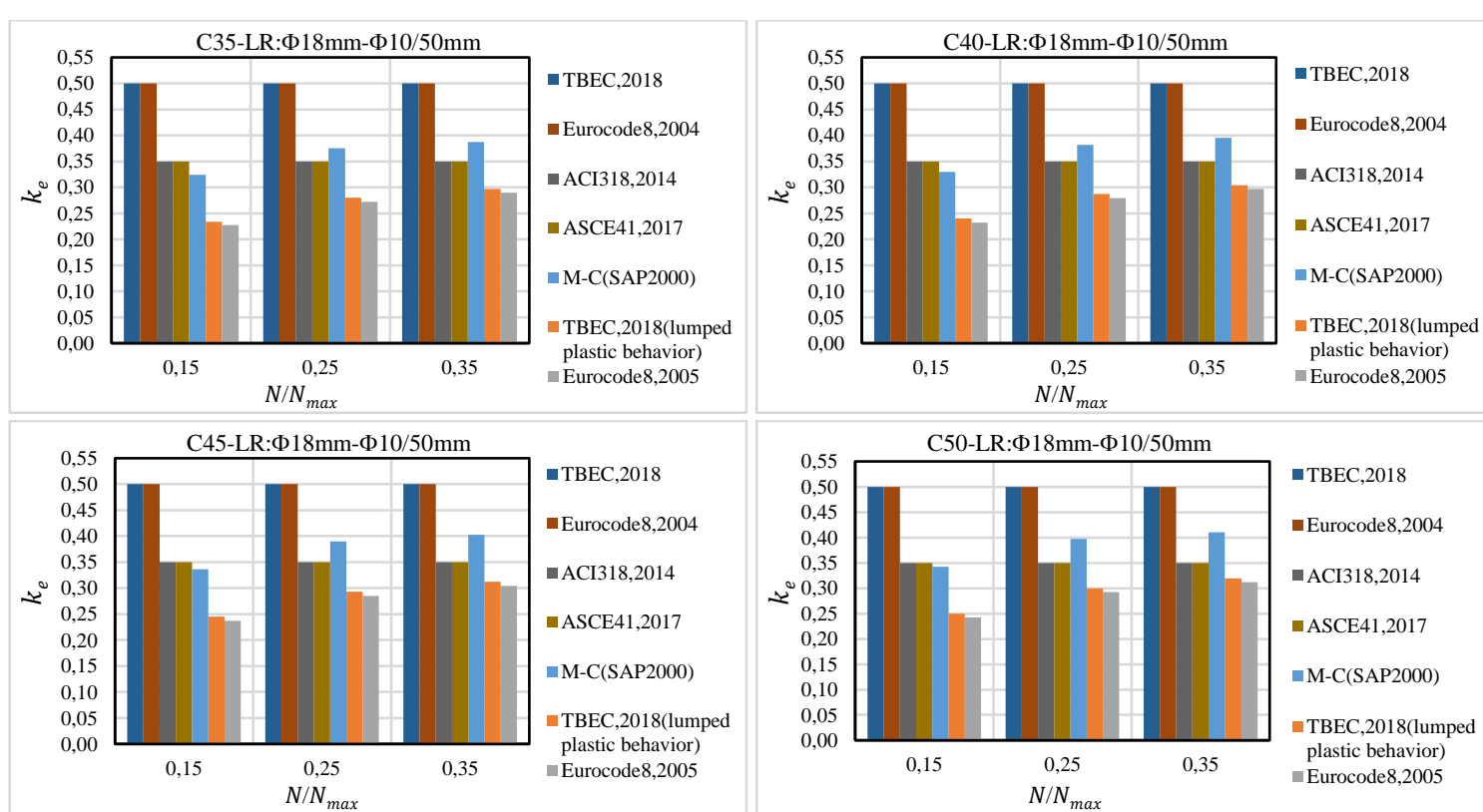

d) Different concrete strength

Fig. 7. Cont'd

The effective section stiffness value of the cracked section given in Eurocode 8 is fixed. The effective section stiffness of the cracked section is considered to be half of the initial stiffness. In Eurocode 8, features such as concrete strength, cross-section geometry, longitudinal and transverse reinforcement ratio and axial force acting on the section are not taken into consideration. Part 3 of Eurocode 8 provides an equation based on momentto-shear ratio and yield rotation, which can be used for the determination of a more accurate effective stiffness. Both the ultimate level and serviceability level loads are addressed in Eurocode 8 for linear and nonlinear analysis. Similarly, in TBEC [11], effective section stiffness is assumed to be constant and effective stiffness coefficient values of the cracked section are 0.50 for shear walls. Effective cross-sectional stiffness of reinforced shear walls modelled according to the lumped plastic behaviour in TBEC [11] can be calculated depending on the effective yield moments, yield rotation and the shear span.

\section{Conclusion}

- Determining the moment-curvature relationship in the design and evaluation of RC elements and obtaining effective section stiffness values are of great importance in order to obtain more realistic results.

- It is observed that the variation of the axial load, longitudinal and transverse reinforcement ratio have an important effect on the momentcurvature behavior of the RC shear walls. The increase in the axial load level causes curvature values to decrease. In cases where the axial load is low, the RC shear walls have a ductile behavior.

- Ultimate moment capacities and curvature of the shear walls increase when the transverse reinforcement spacing decreases. The ductile behavior for RC shear walls is observed due to the increment of curvature ductility with the increase of the transverse reinforcement ratio. The increase in the transverse reinforcement diameter increases the ultimate moment, yield curvature, ultimate curvature and curvature ductility values, but yield moment values remain almost constant. 
- Yield and ultimate moment capacities of the members increase with the increment of longitudinal reinforcing ratio for the shear wall. Curvature ductility values decrease as the longitudinal reinforcement ratio increases while other parameters kept constant.

- In commonly used seismic codes, the effective stiffness of RC members is expressed as a ratio of their stiffness, calculated on the basis of their gross section properties. As can be seen from the comparison results, the effective stiffness values calculated from the moment-curvature analysis and from different codes are different from each other. The reason for this is that different parameters are taken into account in calculating the effective stiffness suggested by different codes.

- Although the effective stiffness of the cracked section is not constant, it depends on the design parameters of the RC structural members. In this study, all design parameters that affect the behavior of $\mathrm{RC}$ shear walls are taken into consideration in order to obtain more realistic results. It is seen that all the design parameters have an effect on the nonlinear momentcurvature relations of the RC shear walls, and the parameters that affect the nonlinear moment-curvature behavior of the sections also affect the effective stiffness of the sections.

- Realistic effective section stiffness can best be derived from moment-curvature relationships. The effective section stiffness reflects not only the effect of cracking but also the behavior of RC elements determined from momentcurvature analyses.

- Taking the effective stiffness higher than the required value will cause the structural stiffness to be overestimated. As a result, problems will arise in the calculation and evaluation of structures.

- Effective stiffness values increase with the increase in the transverse reinforcement diameter, the decrease in the transverse reinforcement spacing, increase in the longitudinal reinforcement diameter of the designed RC shear walls. Due to the increase of axial force, the effective stiffness of RC shear walls have increased.

- In the relations suggested for the effective section stiffness coefficient, the confining effect is not taken into account as in the regulations. Therefore, it means neglecting the effects of parameters such as concrete strength, confining effect and axial force acting on the section. This situation can lead to unrealistic results in the design and evaluation of RC elements. For this reason, determining the moment-curvature relationship in the design and evaluation of RC elements and obtaining effective section stiffness values are of great importance in order to obtain more realistic results.

\section{Declaration of conflicting interests}

The author(s) declared no potential conflicts of interest with respect to the research, authorship, and/or publication of this article.

\section{References}

[1] Avşar Ö, Bayhan B, Yakut A (2014) Effective flexural rigidities for ordinary reinforced concrete columns and beams. The Structural Design of Tall and Special Buildings 23: 463-482.

[2] Das S, Choudhury S (2019) Influence of effective stiffness on the performance of rc frame buildings designed using displacement-based method and evaluation of column effective stiffness using ANN. Engineering Structures 197: 109354.

[3] Hu H-S, Nie J-G, Wang Y-H (2016) Effective stiffness of rectangular concrete filled steel tubular members. Journal of Constructional Steel Research 116: 233-246.

[4] Çağlar N, Demir A, Ozturk H, Akkaya A (2015) A simple formulation for effective flexural stiffness of circular reinforced concrete columns. Engineering Applications of Artificial Intelligence 38: 79-87

[5] Elwood K.J, Eberhard M.O (2009) Effective stiffness of reinforced concrete columns. ACI Structural Journal 106(4): 476-484.

[6] Vidović D, Grandić D, Šćulac P (2012) Effective stiffness for structural analysis of buildings in earthquake. 4th International Conference Civil Engineering-Science and Practice, Žabljak, 811818. 
[7] Zhang Z, Li B (2016) Effective stiffness of nonrectangular reinforced concrete structural walls. Journal of Earthquake Engineering 22(39): 382403.

[8] Li B, Xiang W (2011) Effective stiffness of squat structural walls. ASCE Journal of Structural Engineering 137(129): 1470-1479.

[9] Kwon J, Ghannoum WM (2016) Assessment of international standard provisions on stiffness of reinforced concrete moment frame and shear wall buildings. Engineering Structures 128: 149-160.

[10] Sharifi M, Shafieian M (2018) Effective stiffness of concrete shear walls based on statistical analysis. Structural Concrete 19(6): 1560-1576.

[11] Rahimian A (2011) Lateral stiffness of concrete shear walls for tall buildings. ACI Structural Journal 108(6): 755-765.

[12] Paulay T, Priestley MJN (1992) Seismic Design of Reinforced Concrete and Masonry Buildings. John Wiley \& Sons: New York.

[13] Panagiotakos TB, Fardis MN (2011) Deformations of reinforced concrete members at yielding and ultimate. ACI Structural Journal 98(2): 135-148.

[14] TBEC: Turkish Building Earthquake Code: Specifications for Building Design under Earthquake Effects, Ankara, 2018.

[15] ACI 318: Building Code Requirements for Reinforced Concrete and Commentary, American
Concrete Institute Committee, 2014, ISBN: 978-087031-930-3.

[16] ASCE Standard 41: Seismic Evaluation and Retrofit of Existing Buildings, (ASCE/SEI 41-17), The American Society of Civil Engineers, Reston, Virginia, 2017, pp 20191-4382, USA.

[17] European Committee for Standardization. Eurocode 8: Design of structures for earthquake resistance: Part 1: General rules, seismic actions and rules for buildings. BS EN 1998-1:2004.

[18] European Committee for Standardization (CEN). Eurocode 8: Design of structures for earthquake resistance: Part 3: Assessment and retrofitting of buildings. BS EN 1998-3, 2004; Brussels, Belgium.

[19] TS500: Requirements for Design and Construction of Reinforced Concrete Structures, Turkish Standards Institute, Ankara, Turkey, 2000.

[20] European Committee for Standardization. Eurocode 2: Design of Concrete Structures-Part 1: General Rules and Rules for Buildings. EN 1992-1-1. December 2004.

[21] SAP2000, Structural Software for Analysis and Design, Computers and Structures, Inc, USA.

[22] Mander JB, Priestley MJN, Park R (1988) Theoretical stress-strain model for confined concrete. Journal of Structural Engineering 114(8): 1804-1826. 